\title{
AVALIAÇÃO CITOLÓGICA DE MEDULA ÓSSEA DE CADELAS DA REGIÃO METROPOLITANA DE CURITIBA, PR
}

\section{Bone Marrow Citologic Evaluation of Bitches from Neighborhood of Curitiba, PR}

Silvana Maris Cirio

Médica Veterinária, Dr. ${ }^{a}$, Prof. ${ }^{a}$ da PUCPR, São José dos Pinhais - PR. e-mail: silvana.cirio@pucpr.br

Rita Mangrich Rocha

Médica Veterinária, M. Sc., Prof. ${ }^{a}$ da PUCPR, São José dos Pinhais - PR. e-mail: rita.rocha@pucpr.br

Luiz Carlos Leite

Médico Veterinário, Dr., Professor, União da Vitória - PR. e-mail: lcmouraleite@pop.com.br

Michelly Carvalho

Graduanda de Medicina Veterinária, São José dos Pinhais - PR. e-mail: silvana.cirio@pucpr.br

Selene Cirio Leite

Graduanda de Medicina Veterinária, São José dos Pinhais - PR. e-mail: tudolica@pop.com.br

Diego Lunelli

Graduando de Medicina Veterinária, São José dos Pinhais - PR. e-mail: tudolica@pop.com.br

Luciana Barbisan Kispergue

Graduanda de Medicina Veterinária, São José dos Pinhais - PR. e-mail: tudolica@pop.com.br

\section{Resumo}

A avaliação da medula óssea é um recurso muito utilizado em Medicina Veterinária para o diagnóstico das doenças do sistema hematopoiético. Foi avaliada a composição celular da medula óssea de cadelas saudáveis, para obter um parâmetro de valores de referência para o mielograma. Na presente pesquisa, estabeleceu-se os valores de referência para mielograma de cadelas saudáveis da Região Metropolitana de Curitiba.

Palavras-chave: Medula óssea; Doença hematopoética; Mielograma canino.

\section{Abstract}

The cytologic evaluation of bane marrow is a very much employed procedure in Veterinary Medicine in regard to the diagnostic of hematopoietic diseases. In order to establish the normal ranges for canines a research has been carried out in regard to the bone marrow cellular composition of healthy bitches from Curitiba Metropolitan Region.

Keywords: Bone marrow; Hematopoietic diseases; Canine mielogram. 


\section{INTRODUÇÃO}

Enquanto que a contagem das células do sangue periférico fornece informações a respeito dos possíveis efeitos da doença e do tratamento, a avaliação morfológica da medula óssea, por citologia ou cortes histológicos, fornece informações mais detalhadas, que passariam despercebidas no exame do sangue periférico (TRAVLOS, 2006). A medula óssea é o principal órgão linfóide e hematopoiético do organismo e sua avaliação tem sido amplamente utilizada não apenas no diagnóstico das doenças do sistema hematopoiético, mas também no estadio das neoplasias e na pesquisa de parasitas. Além disso, é cada vez mais comum a utilização dessa técnica como via para procedimentos terapêuticos, como a coleta de material e a infusão de medicamentos. Em geral, as indicações para a avaliação da medula óssea surgem após a constatação de anormalidades observadas no hemograma (ALENCAR et al., 2002).

Com o objetivo de obter um parâmetro de valores de referência normais para o mielograma canino avaliou-se a celularidade, os megacariócitos e a contagem diferencial das células da medula óssea de cadelas saudáveis da região metropolitana de Curitiba, submetidas à eutanásia junto ao Centro de Controle de Zoonoses de São José dos Pinhais.

\section{MATERIAIS E MÉTODOS}

A colheita de medula óssea de 15 cadelas foi realizada no Centro de Controle de Zoonoses de São José dos Pinhais, após a rotina de eutanásias. O local de eleição para a colheita foi a crista ilíaca, com agulhas descartáveis $40 \times 16$ e seringas de $5 \mathrm{ml}$. Para cada animal, foram realizados três esfregaços em lâmina para microscopia e submetidos à coloração de May-Grümwald Giemsa.

A avaliação dos esfregaços de medula óssea foi feita em microscopia óptica. Com a objetiva de 10x, analisou-se a celularidade, cujo parâmetro é a relação entre gordura e células, além da presença e da quantidade de megacariócitos.

Foram avaliadas 500 células por lâmina, para o exame diferencial. As lâminas foram analisadas sob imersão a óleo, classificando-as dentro dos dois grandes grupos: 1) mielóide ou células brancas; ou 2) eritróide ou células vermelhas. Na identificação das células, foram consideradas as características morfológicas de núcleo e citoplasma, sua coloração e tamanho. Em seguida, avaliou-se o grau de maturidade de cada célula, colocandoas dentro de seu grupo etário - maturas e imaturas. Ao final da contagem, foi calculado o percentual de cada grupo celular e de células eritróides e mielóides maturas. A relação mielóide/eritróide foi calculada dividindose o total das células mielóides pelo total das células eritróides. Os valores de referência descritos por Harvey (2001) e Weiss e Smith (2002) serviram de parâmetro para a interpretação dos resultados.

\section{RESULTADOS}

Os valores de medula óssea das cadelas apresentados nas tabelas a seguir refletem os dados coletados de uma população canina aleatória, composta por cinco cadelas jovens e 10 cadelas adultas, sendo selecionadas as que apresentavam boas condições físicas.

$\mathrm{Na}$ Tabela 1 estão relacionados os resultados da avaliação de celularidade e presença de megacariócitos encontrados para cada animal, avaliados sob objetiva de 10x. Nas Tabelas 2 e 3 estão relacionados os resultados da contagem diferencial de células da linhagem mielóide e eritróide, respectivamente, referentes a cada animal e avaliados sob objetiva de 100x. Na Tabela 4 observa-se a relação mielóide/eritróide e o percentual de eritrócitos e mielócitos maturos. Nesse exame foi utilizado imersão a óleo (objetiva 100x). A média dos valores encontrados nas cinco fêmeas jovens, para a celularidade foi de $68 \%$, e nas dez fêmeas adultas, 54\%. Dos demais parâmetros do mielograma, para ambas as faixas etárias, as médias foram: número de megacariócitos $(95,33)$, células eritróide $(43,86 \%)$, sendo $41,55 \%$ maturas e 2,31\% imaturas; células mielóide (56,14\%), sendo 53,48\% maturas e 2,66\% imaturas. A relação mielóide/eritróide foi de 1,28:1,00. 
TABELA 1 - Celularidade e megacariócitos de aspirado de medula óssea de cadelas adultas e jovens da região metropolitana de Curitiba, PR

Table 1 - Celular and megakariocytes from the young and adults bitches bone marrow aspirates from the Curitiba Metropolitan Region, PR

\begin{tabular}{lcc}
\hline Faixa Etária & Celulatidade \% & Megacariócitos $\mathrm{N}^{\circ}$ \\
\hline Jovem 1 & 75 & 89 \\
Jovem 2 & 65 & 48 \\
Jovem 3 & 70 & 38 \\
Jovem 4 & 65 & 136 \\
Jovem 5 & 65 & 92 \\
Adulto 1 & 60 & 209 \\
Adulto 2 & 50 & 124 \\
Adulto 3 & 60 & 32 \\
Adulto 4 & 40 & 95 \\
Adulto 5 & 50 & 99 \\
Adulto 6 & 60 & 95 \\
Adulto 7 & 50 & 158 \\
Adulto 8 & 60 & 46 \\
Adulto 9 & 60 & 80 \\
Adulto 10 & 50 & 89 \\
\hline
\end{tabular}

TABELA 2 - Contagem diferencial de células mielóide maturas e imaturas de aspirado de medula óssea de cadelas adultas e jovens da região metropolitana de Curitiba, PR Table 2 - Differential counting of mature and immature cells at the bone marrow aspirates from young and adults bitches from Curitiba Metropolitan Region, PR

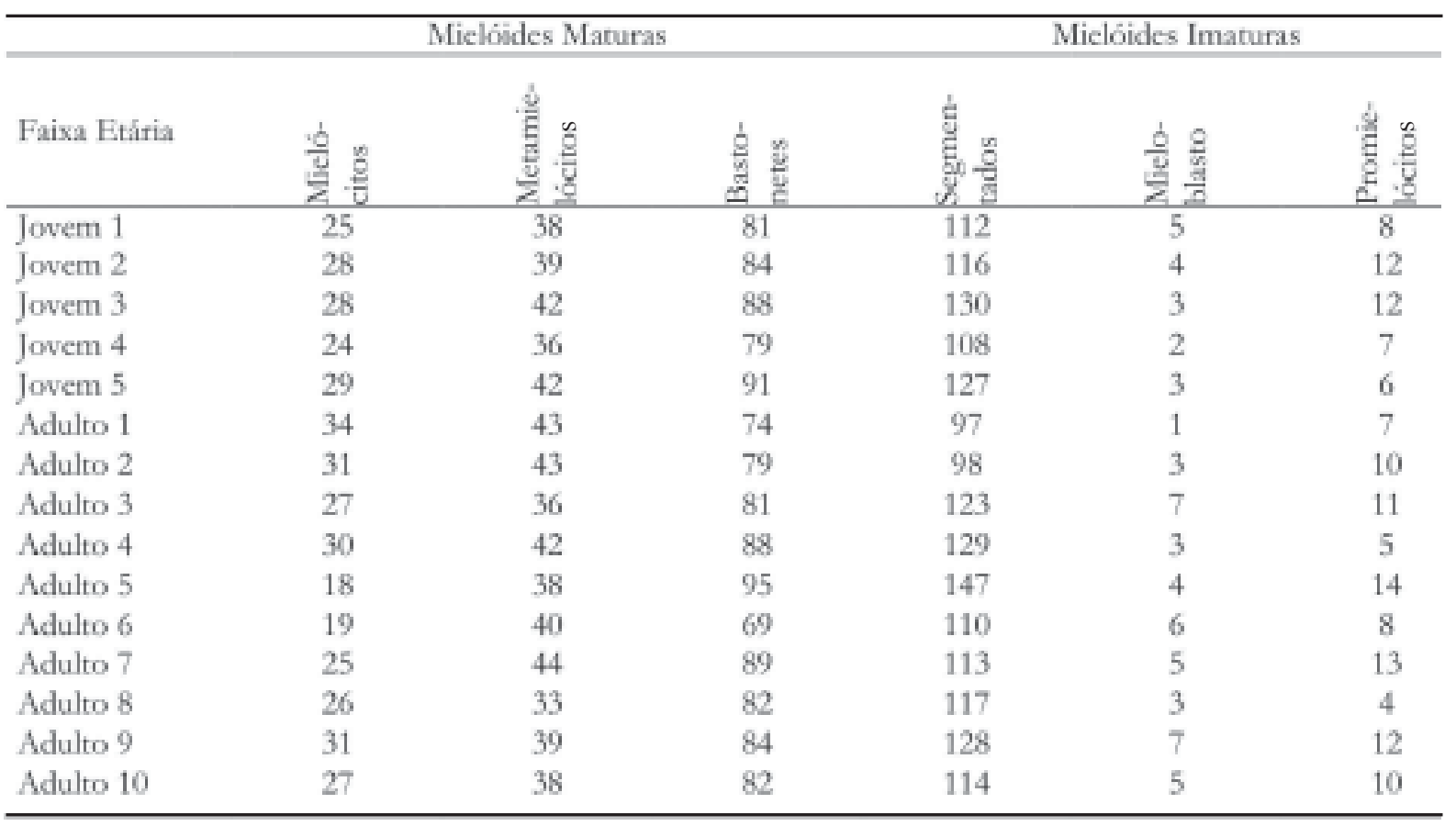


TABELA 3 - Contagem diferencial de células eritróides maturas e imaturas de aspirado de medula óssea de cadelas adultas e jovens da região metropolitana de Curitiba, PR Table 3 - Mature and immature erythroid cells from young and adult bitches bone marrow aspirates from Curitiba Metropolitan Region, PR

\begin{tabular}{ccccc}
\hline \multirow{2}{*}{ Faixa etäria } & \multicolumn{2}{c}{ Eritróides Maturas } & \multicolumn{2}{c}{ Eritróides Imaturas } \\
\cline { 2 - 5 } & Rubrócitos & Metarubrócitos & Rubroblastos & Prorubrócitos \\
\hline Jovem 1 & 149 & 70 & 3 & 9 \\
Jovem 2 & 131 & 78 & 2 & 6 \\
Jovem 3 & 103 & 79 & 5 & 10 \\
Jovem 4 & 162 & 69 & 4 & 9 \\
Jovem 5 & 119 & 78 & 1 & 4 \\
Adulto 1 & 156 & 73 & 3 & 12 \\
Adulto 2 & 148 & 70 & 5 & 13 \\
Adulto 3 & 122 & 77 & 4 & 2 \\
Adulto 4 & 139 & 61 & 1 & 4 \\
Adulto 5 & 130 & 47 & 3 & 10 \\
Adulto 6 & 166 & 69 & 3 & 7 \\
Adulto 7 & 144 & 58 & 1 & 12 \\
Adulto 8 & 151 & 72 & 5 & 7 \\
Adulto 9 & 124 & 57 & 6 & 2 \\
Adulto 10 & 140 & 74 & 2 & \\
\hline
\end{tabular}

TABELA 4 - Relação mielóide: eritróide e percentual eritróides e mielóides maturos em aspirado de medula óssea de cadelas adultas e jovens da região metropolitana de Curitiba, PR Table 4 - Myeloid-erythroid ratio and mature erythroid myeloid at bone marrow aspirates from young and adult bitches from Curitiba Metropolitan Region, PR

\begin{tabular}{lccc}
\hline Faixa Etária & Relaçăo M:E & Eritróides Maturos \% & Mielóides Maturos \% \\
\hline Jovem 1 & $1,10: 1,00$ & 94,80 & 95,16 \\
Jovem 2 & $1,30: 1,00$ & 96,31 & 94,34 \\
Jovem 3 & $1,53: 1,00$ & 92,38 & 95,04 \\
Jovem 4 & $1,04: 1,00$ & 94,67 & 96,48 \\
Jovem 5 & $1,43: 1,00$ & 97,52 & 96,97 \\
Adulto 1 & $1,04: 1,00$ & 93,08 & 96,08 \\
Adulto 2 & $1,06: 1,00$ & 92,37 & 95,07 \\
Adulto 3 & $1,32: 1,00$ & 92,55 & 93,68 \\
Adulto 4 & $1,46: 1,00$ & 98,52 & 97,30 \\
Adulto 5 & $1,71: 1,00$ & 96,19 & 94,30 \\
Adulto 6 & $1,01: 1,00$ & 94,75 & 94,44 \\
Adulto 7 & $1,37: 1,00$ & 95,73 & 93,77 \\
Adulto 8 & $1,12: 1,00$ & 94,89 & 97,35 \\
Adulto 9 & $1,51: 1,00$ & 90,95 & 93,68 \\
Adulto 10 & $1,18: 1,00$ & 95,96 & 94,22 \\
\hline
\end{tabular}




\section{DISCUSSÃO E CONCLUSÕES}

A crista ilíaca é o local de eleição para a aspiração da amostra de medula óssea tanto para seres humanos quanto para os animais, e como salienta Bain (2001), a preocupação com relação ao conforto e segurança do paciente deve estar sempre presente. Neste estudo a colheita da amostra foi a partir de cadáveres, mas houve o cuidado de se fazer o procedimento como em um paciente vivo, justamente para que a amostra fosse o mais compatível possível com a realidade.

As agulhas descartáveis 40 × 16 utilizadas na obtenção das amostras de medula óssea das cadelas mostraram-se eficientes. Alencar et al. (2002) recomendam que as agulhas sejam específicas para esse fim e consideram que é o maior investimento para esse exame. Uma vez que as agulhas descartáveis podem fazer parte do material usado para uma adequada colheita de medula óssea, o custo do exame tende a ser menor. Os mesmos autores, assim como Bain (2001) recomendam para os esfregaços a utilização de corantes tipo Romanowsky, com preferência à coloração de May-Grümwald Giemsa. Esta mostrou-se excelente para a avaliação citológica da medula óssea devido às suas qualidades tintoriais, além da rapidez na coloração das lâminas, o que é fundamental para obter-se um resultado seguro.

As médias dos valores encontrados nas cinco fêmeas jovens e nas dez adultas são compatíveis com os de referência descritos por Harvey (2001) e Weiss (2002), que serviram de parâmetro para a interpretação dos resultados. Dessa forma, foram estabelecidos os valores de referência para o mielograma de cadelas saudáveis da região metropolitana de Curitiba, PR, que servirão como parâmetro para a interpretação das patologias de medula óssea.

\section{REFERÊNCIAS}

ALENCAR, N. X. et al. Mielograma: indicações e colheita do material. Continuous Education Journal CRMV-SP, v. 5, p. 157-163, 2002. Parte I.

BAIN, B. J. Bone marrow aspiration. Journal Clinical Pathology, n. 54, v. 9, p. 657-663, 2001.

HARVEY, J. W. Atlas of veterinary hematology: blood and bone marrow of domestic animals. Philadelphia: W. B. Saunders Company, 2001.

TRAVLOS, G. S. Normal structure, function, and histology of the bone marrow. Toxicological Pathology, n. 34, v. 5, p. 548- 565, 2006.

WEISS, D. J.; SMITH, S. A. Collection and assessment of canine bone marrow. Compendium, v. 24, p. 670-678, sept. 2002.

Recebido em: 07/10/2006

Received in: 10/07/2006

Aprovado em: 30/03/2007

Approved in: 03/30/2007 